\title{
APLIKASI ALAT BANTU PEMBELAJARAN SISWA SEKOLAH DASAR MENGGUNAKAN METODE MULTIMEDIA DEVELOPMENT LIFE CYCLE (MDLC)
}

\author{
Yusuf Sumaryana*1, Missi Hikmatyar² \\ 1,2Fakultas Teknik Universitas Perjuangan; Jalan Peta No. 177 Kota Tasikmalaya \\ e-mail: *1yusuf.sumaryana@gmail.com, ${ }^{2}$ hikmatyarmissi@gmail.com
}

\begin{abstract}
Abstrak
Model pembelajaran yang beragam, mengharuskan setiap kegiatan belajar mengajar jangan sampai menjadikan para siswa merasa bosan. Diperlukan adanya suatu alat bantu yang digunakan guna mendukung kegiatan belajar mengajar yang lebih menarik. Salah satu fasilitas yang bisa digunakan adalah teknologi komputer multimedia dimana para siswa bisa menggunakan perangkat lunak pembelajaran multimedia interaktif. Multimedia digunakan sebagai sarana pembelajaran yang diharapkan dapat meningkatkan minat belajar siswa, karena terdiri dari unsur suara dan gambar. Aplikasi yang dibuat diperuntukan bagi siswa kelas V Sekolah Dasar. Pengembangan pernagat lunak ini menggunakan metode Multimedia Development Life Cycle (MDLC). Metode ini terdiri dari ada 6 (enam) tahapan yang harus dilakukan dalam proses pelaksanaannya. Adobe CS digunakan untuk membuat aplikasi multimedia yang telah dirancang.
\end{abstract}

Kata Kunci: Mutimedia, MDLC, Pembelajaran

\section{THE APPLICATION OF PRIMARY SCHOOL LEARING TOOLS USING MULTIMEDIA DEVELOPMENT METHOD LIFE CYCLE (MDLC)}

\begin{abstract}
Various learning models require that every teaching and learning activity does not make students feel bored. It is necessary to have a tool that is used to support teaching and learning activities that are more interesting. One of the facilities that can be used is multimedia computer technology where students can use interactive multimedia learning software. Multimedia is used as a learning tool which is expected to increase student interest in learning, because it consists of sound and image elements. Applications made are intended for fifth grade elementary school students. This software development uses the Multimedia Development Life Cycle (MDLC) method. This method consists of 6 (six) stages that must be carried out in the implementation process. Adobe CS is used to create multimedia applications that have been designed.
\end{abstract}

Keywords: Multimedia, MDLC, Learning

\section{Pendahuluan}

Pembelajaran metode ceramah yang biasa diselenggarakan masih memiliki kelemahan sehingga diperlukan sebuah model pembelajaran yang sesuai dengan kondisi saat ini (Mustika 2018) [1]. Diantara kelemahan itu adalah metode komunikasi yang berjalan hanya satu arah, sehingga mengurangi interaksi antara siswa dan guru (Toha 2020) [2]. Model pembelajaran menggunakan alat bantu pembelajaran diharapkan dapat meningkatkan minat belajar para siswa Sekolah Dasar. Hali ini sejalan dengan diterapkan nya Revolusi Industri 4.0 yang menjadikan komputer sebagai salah satu bagian teknologi yang saat ini 
semakin berkembang fungsi nya. Dengan tersedianya alat bantu pembelajaran berupa aplikasi perangkat lunak dapa memberikan pengalaman belajar yang lebih variatif.

Aplikasi alat bantu pembelajaran interaktif ini juga diharapkan dapat memfasilitasi metode pembelajaran siswa sekolah dasar agar lebih menarik.

Beberapa penelitian di bidang multimedia menunjukan berbagai macam perbedaan baik dari metode yang digunakan maupun objek pembahasan yang disajikan.

Toha 2020, melakukan penelitian tentang pembuatan aplikasi multimedia, yang menitikberatkan pada pembelajaran matematika tingkat Sekolah Dasar. Penelitian ini didasarkna karena pembelajaran konvensional dianggap kurang mengeksplorasi wawasan pengetahuan siswa, sikap dan prilaku siswa. Sehingga dengan dibuatnya aplikasi pembelajaran interaktif diharapkan pembelajaran matematika menjadi lebih menarik [1].

Syahroni 2018, melakukan penelitian dengan topik Pengembangan Media Pembelajaran Interaktif Berbasis Komputer dalam Pembelajaran Matematika, Materi Bilangan pada Kelas 3 SD. Penelitian ini dilakukan dengan tujuan bagaimana pengembangan media pembelajaran berbasis multimedia 3D dibuat. Adapun proses pengembangan penelitian ini menggunakan metode ADDIE [3].

Adapun penelitian yang penulis lakukan adalah pembuatan aplikasi multimedia interaktif yang ditujukan untuk siswa SD. Materi yang disajikan berdasarkan buku Tematik untuk kelas 5 SD. Proses pengerjaan penelitian ini menggunakan alur yang terdapat pada metode Multimedia Development Life Cycle (MDLC). Software yang digunakan untuk pembuatan aplikasi multimedia ini menggunakan Adobe CS.

\section{Metode Penelitian}

\section{Tinjauan Pustaka}

\section{Multimedia}

Istilah multimedia tidak saja merujuk pada topik, materi, mata pejalaran di sekolah dan mata kuliah di perguruan tinggi, tetapi lebih dari itu juga merujuk pada bidang keahlian, profesi dan bahkan merujuk pada perangkat untuk memainkan program tersebut.

Secara etimologis multimedia berasal dari kata multi dan media. Multi berarti banyak atau jamak dan media berarti sarana untuk menyampaikan pesan atau informasi berupa teks, gambar, suara, video. Jadi secara bahasa istilah multimedia merupakan kombinasi banyak atau beberapa media seperti teks, gambar, suara, video yang digunakan untuk menyampaikan pesan atau informasi. Pengertian ini memang masih sangat umum yakni masih belum secara spesifik menunjukkan bagaimana bentuknya dan proses pembuatannya dan belum juga tersirat apakah dimanipulasi secara manual maupun digital [4].

\section{Multimedia Development Life Cycle (MDLC)}

Multimedia Development Life Cycle (MDLC) terdiri dari 6 (enam) tahapan kegiatan yang dilakukan, yaitu: [5]

\section{a. Konsep (Concept)}

Tahap konsep merupakan tahap awal dalam siklus MDLC. Pada tahap konsep, dimulai dengan menentukan tujuan pembuatan apliaksi serta menentukan pengguna aplikasi tersebut.

\section{b. Perancangan(Design)}

Konsep yang sudah matang akan memudahkan dalam menggambarkan apa yang harus dilakukan. Tujuan dari tahap perancangan adalah membuat spesifikasi secara terperinci mengenai arsitektur proyek, tampilan dan kebutuhan material proyek, serta gaya. Tahap ini menggunakan storyboard untuk menggambarkan rangkaian cerita atau deskripsi tiap scene sehingga dapat dimengerti oleh pengguna, dengan mencantumkan semua objek multimedia dan tautan ke scene lain. 


\section{c. Pengumpulan Bahan(Material Collecting)}

Material Collecting adalah tahap pengumpulan bahan yang sesuai dengan kebutuhan.Bahan-bahan tersebut antara lain gambar, foto, animasi, video, audio, serta teks baik yang sudah jadi ataupun yang masih perlu dimodifikasi sesuai dengan kebutuhan yang ada. Bahan-bahan tersebut dapat diperoleh secara gratis atau dengan pemesanan kepada pihak lain sesuai dengan rancangan yang telah dibuat pada tahap sebelumnya.

d. Pembuatan(Assembly)

Tahap assembly adalah tahap pembuatan keseluruhan bahan multimedia. Aplikasi yang akandibuat didasarkan pada tahap design, seperti storyboard. Tahap ini biasanya menggunakan perangkat lunak authoring.

\section{e. Pengujian(Testing)}

Pengujian dilakukan untuk memastikan bahwa hasil pembuatan aplikasi multimedia sesuai dengan rencana. Ada dua jenis pengujian yang digunakan, yaitu pengujian alpha dan pengujian beta. Pengujian alpha seperti menampilkan tiap halaman, fungsi tombol serta suara yang dihasilkan. Jika ada malfunction maka aplikasi akan segera diperbaiki. Jika telah lolos dalam pengujian alpha maka akan dilanjutkan dengan pengujian beta. Pengujian beta adalah pengujian yang dilakukan oleh pengguna, dengan membuat kuisioner tentang aplikasi yang dibuat.

\section{f. Distribusi(Distribution)}

Tahap ini adalah tahap terakhir dalam siklus pengembangan multimedia. Pendistribusian dapat dilakukan setelah aplikasi dinyatakan layak pakai.Pada tahap ini, aplikasi akan disimpan dalam suatu media penyimpanan seperti $C D$, perangkat mobile atau situds web. Jika media penyimpanan tidak cukup untuk menampung aplikasinya, kompresi terhadap aplikasi tersebut akan dilakukan.Tahap evaluasi termasuk ke dalam tahap ini. Adanya evaluasi sangat dibutuhkan untukpengembangan produk yang sudah dibuat sebelumnya agar menjadi lebih baik.

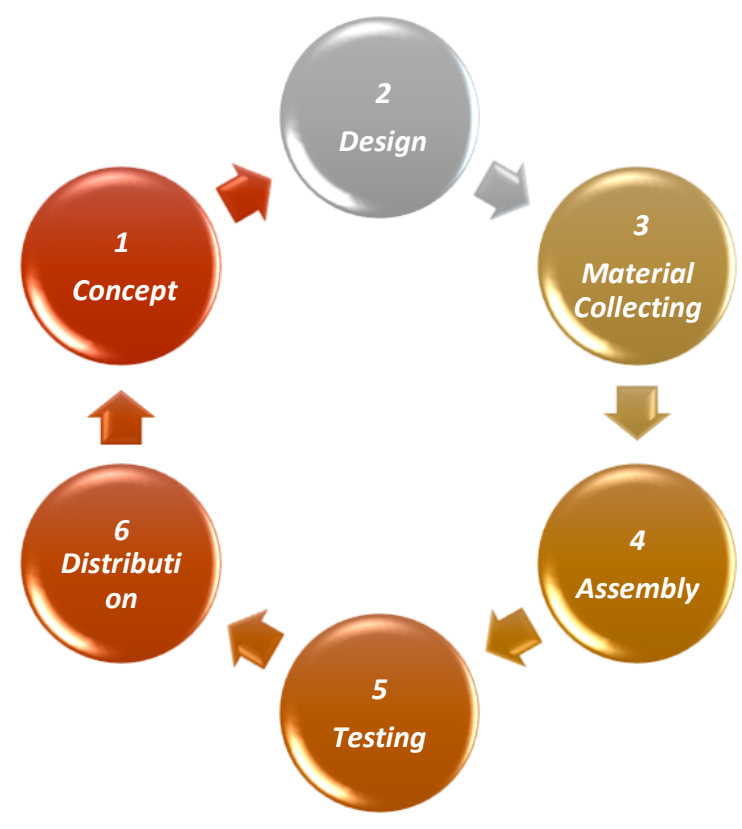

Gambar 1 Tahapan MDLC 


\section{Diagram UML}

UML (Unified Modeling Language) merupakan sekumpulan diagram yang digunakan untuk melakukan penyamarataan terhadap sebuah sistem atau software berbasis objek. Diagram ini dapat digunakan untuk mempermudah pengembangan aplikasi yang berkelanjutan. UML dapat dikatakan juga sebagai perkembangan, bahasa pemodelan di bidang rekayasa perangkat lunak yang bertujuan untuk menyediakan cara standar untuk menggambarkan desain sebuah sistem. UML terdiri dari banyak elemen-elemen grafis yang digabungkan dalam bentuk diagram. Tujuan representasi elemen-elemen grafis ke dalam diagram adalah untuk menyajikan berbagai sudut pandang dari sebuah sistem berdasarkan fungsi masing-masing diagram tersebut. Kumpulan dari berbagai sudut pandang inilah yang disebut sebuah model.[6]

UML sangat penting untuk digunakan oleh seorang analis sistem. Ada beragam manfaat yang diperoleh dari UML yaitu dapat memanajemen kompleksitas dari sistem, mendeteksi kesalahan yang mungkin terjadi ketika diimplementasikan, menjelaskan tata kerja dari sistem kepada para pihak yang berkepentingan (stakeholders). [7]

Pemodelan akan membrikan gambaran yang jelas mengenai sistem yang akan dibuat baik dari sisi sistem maupun fungsional. [8]

\section{Hasil}

\section{Tahap Konsep.}

Pada tahap ini penulis melakukan pendefinisian berbagai hal yang berkaitan dengan aplikasi yang akan dibuat secara umum, seperti yang disajikan pada tabel 1.

Tabel 1 Konsep Umum

\begin{tabular}{|l|l|}
\hline Judul & $\begin{array}{l}\text { Aplikasi Alat Bantu Pembelajaran Siswa Sekolah Dasar } \\
\text { Berbasis Multimedia Menggunaka Metode Multimedia } \\
\text { Development Life Cycle (MDLC) }\end{array}$ \\
\hline Audiens & Murid Kelas 5 Sekolah Dasar \\
\hline Durasi & Tak Terbatas \\
\hline Image & Format *.png untuk image dan *.gif untuk animasi \\
\hline Audio & Backsound dengan format*.mp3 \\
\hline Konten & Materi pembelajaran, quiz \\
\hline Sumber materi & Buku terbitan Kementrian dan Kebudayaan RI 2017 \\
\hline
\end{tabular}

\section{Tahap Desain.}

Tahap desain ini meliputi desain Use Case diagram dan desain antar muka.

Use case diagram bisa mendeskripsikan sebuah interaksi antara satu atau lebih aktor dengan sistem yang akan dibuat. [8]

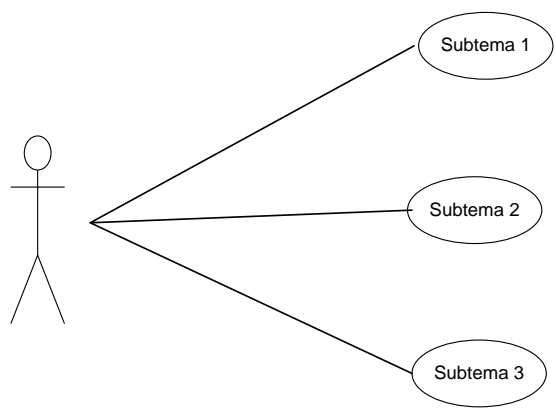

Gambar 2 Use Case diagram. 


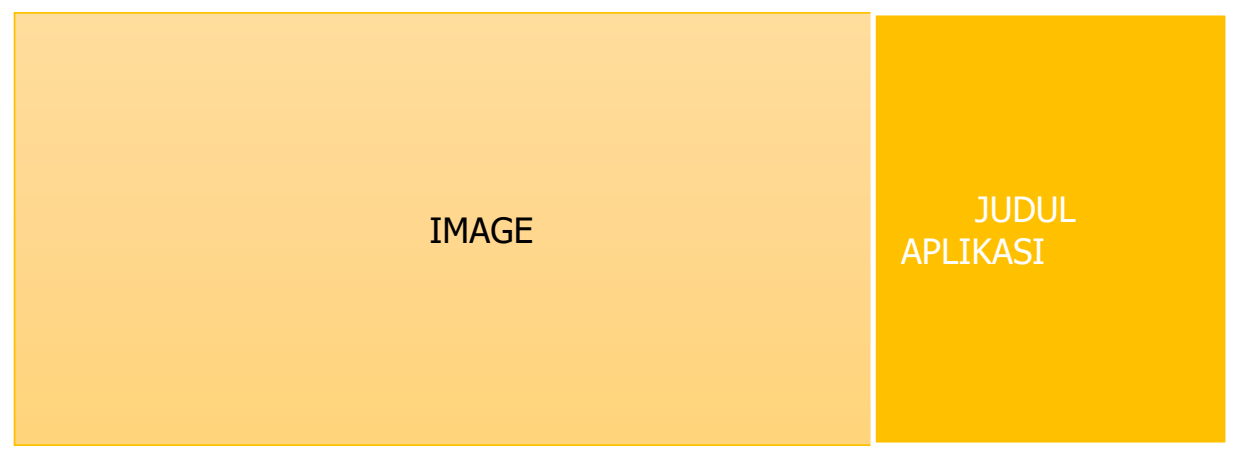

Gambar 3 Rancangan Antarmuka Menu Utama.

\section{Tahap Pengumpulan Bahan}

Pada tahapan ini dilakukan pengumpulan material yang akan digunakan dalam aplikasi yang akan dibuat. Baik itu berupa gambar suara, maupun gambar bergerak yang diperlukan. Serta penentuan jenis huruf yang akan digunakan. Material yang dikumpulkan diperoleh dari beberapa layanan media yang tersedia di internet.

Dalam melakukan pengumpulan bahan. Setiap material yang di kumpulkan kemudian dipilih bahan yang relevan dengan tingkat pendidikan siswa dan tentu harus sesui dengan karakteristik materi dan aplikasi yang akan dibuat.

\section{Tahap Pembuatan}

Pada tahapan ini mulai dilakukan pengkodean menggunakan software Adobe CS. Berikut ini ditampilkan beberapa bagian kode program yang dihasilkan.

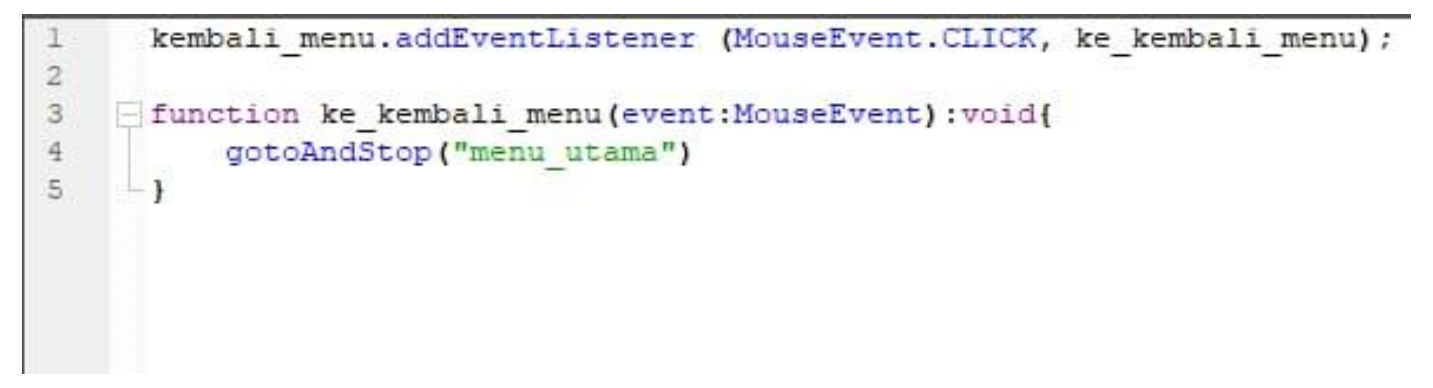

Gambar 4 Kode Program 1 


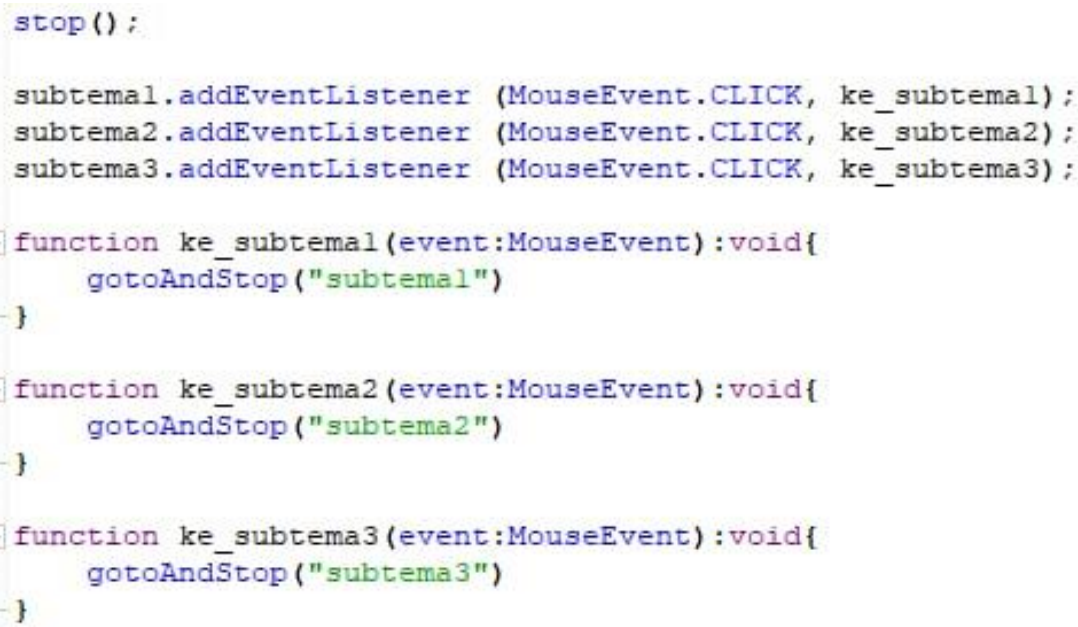

Gambar 5 Kode Program 2

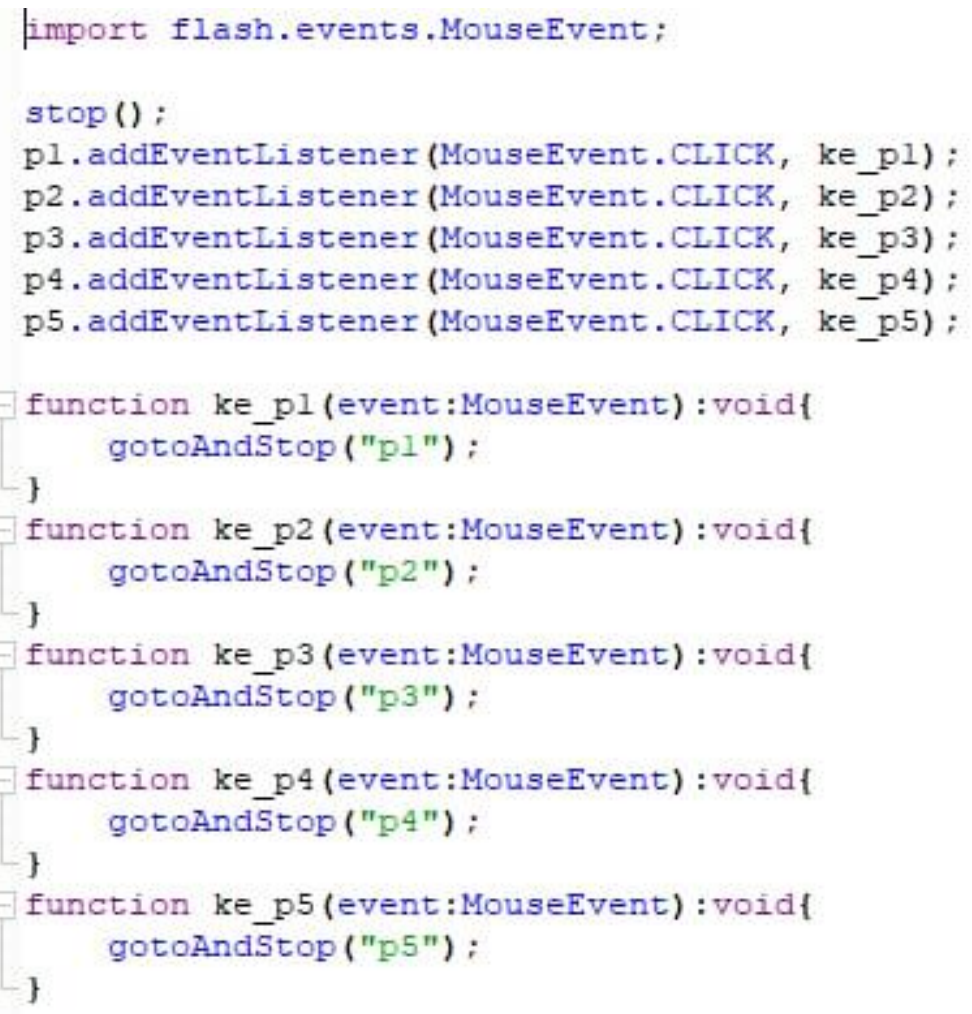

Gambar 6 Kode Program 3

\section{Tahap Pengujian}

Pada tahapan ini dilakukan pengujian terhadap fungsi-fungsi tombol dan suara yang dihasilkan. Dari hasil pengujian diperoleh hasil semua tombol berfungsi dengan baik. 


\section{Tahap Distribusi.}

Pada tahapan ini, aplikasi yang dibuat disimpan pada hardisk laptop agar bisa di copy ke media lain yang diperlukan. Bentuk file yang dihasilkan berupa file *.fla dan *.exe. Aplikasi yang sudah jadi hanya bisa dijalankan pada system operasi Windows.

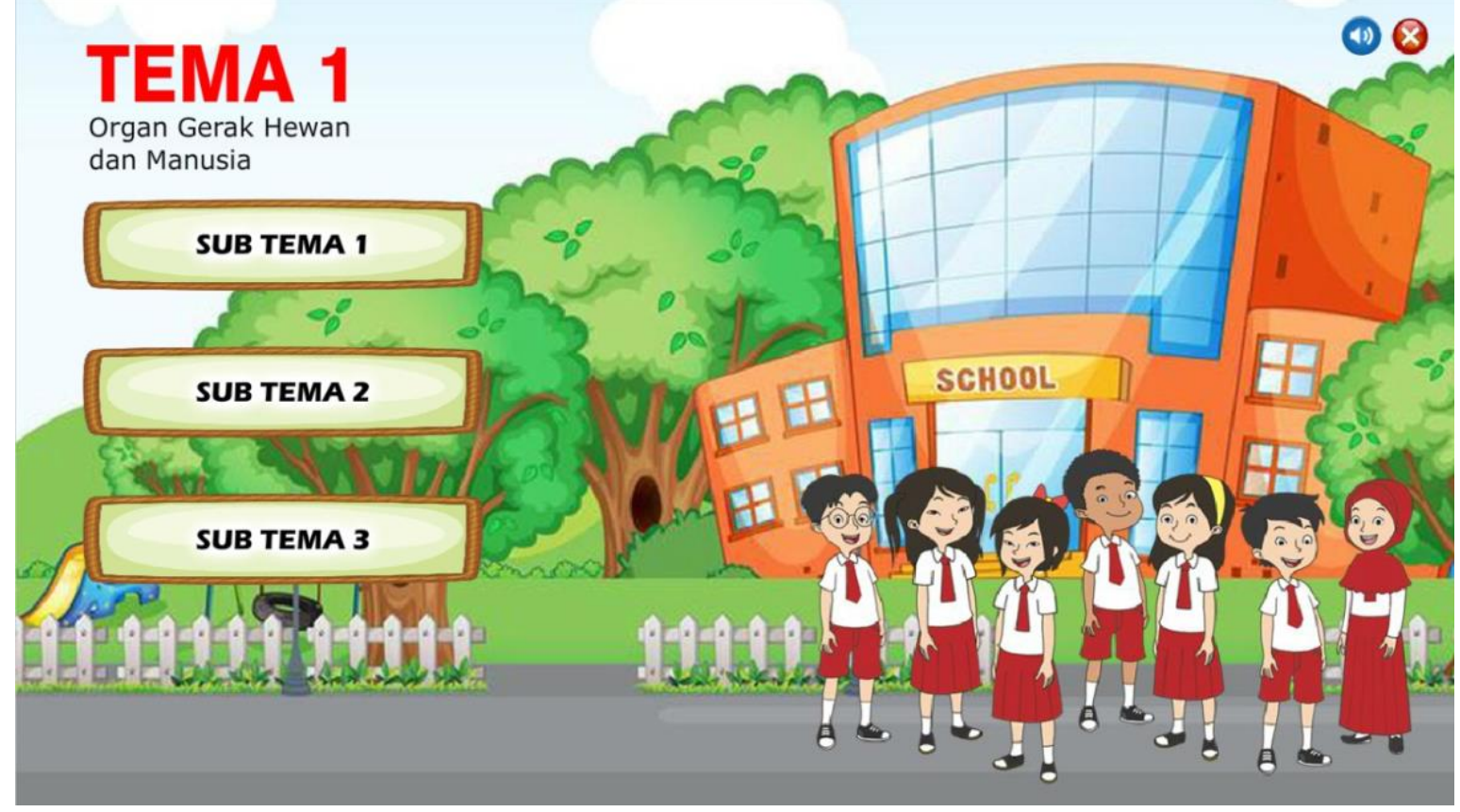

Gambar 7 Tampilan Form Menu Utama

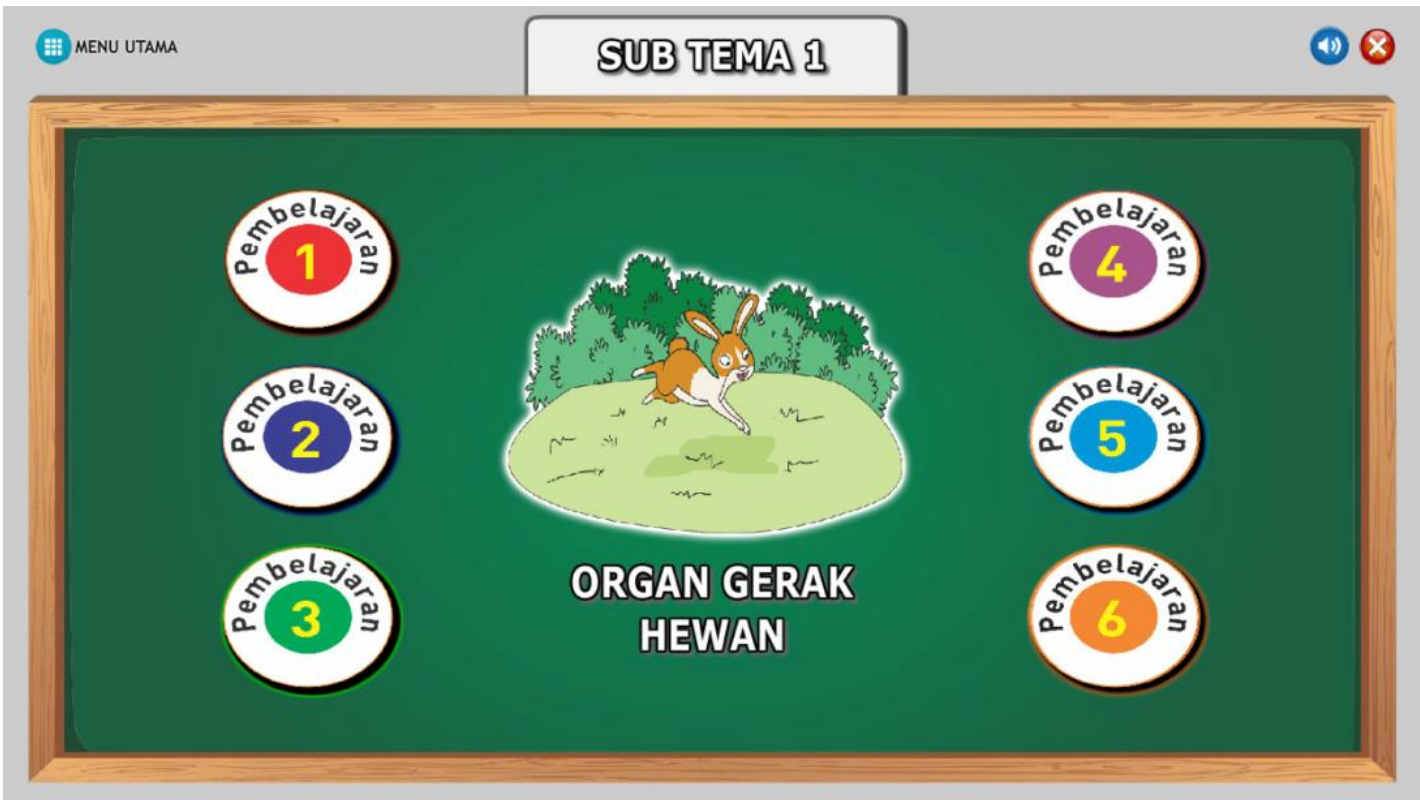

Gambar 8 Tampilan Form Sub Tema 1 


\section{Kesimpulan}

Kesimpulan dari penelitian ini adalah sebagai berikut :

1. Implementasi Aplikasi Alat Bantu Pembelajaran Siswa Sekolah Dasar Berbasis Multimedia Menggunaka Metode Multimedia Development Life Cycle (MDLC) ini menghasilkan sebuah aplikasi pembelajaran untuk siswa kelas 5 SD.

2. Perangkat lunak yang digunakan dalam pembuatan aplikasi adalah Adobe Flash Professional CS6.

3. Aplikasi ini berjalan pada sistem operasi Microsoft Windows.

Adapun saran-saran yang diberikan oleh penulis sebagai berikut:

1. Penambahan variasi latihan soal pada tiap pembelajaran

2. Pembuatan aplikasi yang berjalan pada sistem operasi lainnya, misal Android segingga bisa lebih praktis dalam penggunaannya.

\section{Daftar Pustaka}

[1] M. Mustika, E. P. A. Sugara, and M. Pratiwi, "Pengembangan Media Pembelajaran Interaktif dengan Menggunakan Metode Multimedia Development Life Cycle," J. Online Inform., 2018, doi: 10.15575/join.v2i2.139.

[2] A. F. M. Toha and F. N. Khasanah, "Media Pembelajaran Interaktif Untuk Mata Pelajaran Matematika," J. Kaji. Ilm., 2020, doi: 10.31599/jki.v20i2.120.

[3] S. Syahroni and M. Nurfitriyanti, "Pengembangan Media Pembelajaran Interaktif Berbasis Komputer dalam Pembelajaran Matematika, Materi Bilangan pada Kelas 3 SD," Form. J. Ilm. Pendidik. MIPA, 2018, doi: 10.30998/formatif.v7i3.2237.

[4] H. Surjono, Multimedia Pembelajaran Interaktif: Konsep dan Pengembangan. 2017.

[5] H. Sugiarto, "Penerapan Multimedia Development Life Cycle Pada Aplikasi Pengenalan Abjad Dan Angka," IJCIT (Indonesian J. Comput. Inf. Technol., 2018.

[6] Model-model Diagram UML. Mei 15, 2019. Diakses pada : 25 September 2020. [Online]. Tersedia di: https://sis.binus.ac.id/2019/05/15/model-model-diagram-uml/

[7] Munawar, Analisis Perancangan Sistem Berorientasikan Objek dengan UML (Unified Modeling Language). 2018.

[8] I. Akil, "Rekayasa Perangkat Lunak Dengan Model Unified Process Studi Kasus: Sistem Informasi Journal," J. Pilar Nusa Mandiri, 2016.

[9] UML Diagram : Use Case Diagram. November 26, 2019. Diakses pada : 25 September 2020. [Online]. Tersedia di: https://socs.binus.ac.id/2019/11/26/uml-diagram-use-case-diagram/ 